\title{
Efficiency and Advantages of Percutaneous Femoroplasty versus Proximal Femoral Replacement for Proximal Femur Metastases
}

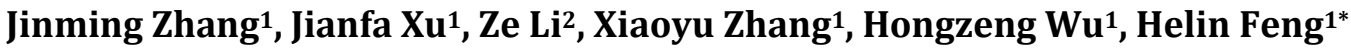 \\ ${ }^{1}$ Department of Orthopedics, The Fourth Hospital of Hebei Medical University, Shijiazhuang, China \\ ${ }^{2}$ Department of Emergency, The Second Hospital of Hebei Medical University, Shijiazhuang, China \\ Email: *fenghelin0311@126.com
}

How to cite this paper: Zhang, J.M., Xu, J.F., Li, Z., Zhang, X.Y., Wu, H.Z. and Feng, H.L. (2018) Efficiency and Advantages of Percutaneous Femoroplasty versus Proximal Femoral Replacement for Proximal Femur Metastases. Open Journal of Orthopedics, $\mathbf{8}$, 351-362.

https://doi.org/10.4236/ojo.2018.810038

Received: August 27, 2018

Accepted: September 27, 2018

Published: September 30, 2018

Copyright (c) 2018 by authors and Scientific Research Publishing Inc. This work is licensed under the Creative Commons Attribution International License (CC BY 4.0).

http://creativecommons.org/licenses/by/4.0/

\section{cc) (i) Open Access}

\begin{abstract}
Background: The proximal femur is the most common site of bone metastasis, and metastasis at this site can cause chronic, intolerable pain and even result in pathologic fractures, thereby negatively affecting patients' quality of life. Selecting an appropriate method for resecting metastasis within the proximal femur requires thorough consideration of various factors, including the biological behavior of the primary tumor, the extent of the femur lesion, the current general systemic condition of the patient, and perioperative risks. Objective: To compare the perioperative safety of and early functional recovery following percutaneous femoroplasty (PFP) and proximal femoral replacement (PFR) in treating patients with metastasis of the proximal femur. Methods: We retrospectively analyzed the cases of 53 patients with proximal femur metastases who received surgical treatment by either PFP $(n=28)$ or PFR ( $n=25)$. Perioperative blood loss, surgical time, and perioperative complications were compared between groups. Pain intensity according to the visual analogue scale (VAS) and early postoperative function according to the Karnofsky Performance Scale (KPS) were evaluated at 3, 7, and 30 days as well as 6 months after surgical treatment. Results: In the PFP group, the VAS scores were lower soon after operation than preoperation $(\mathrm{P}<0.05)$. In the PFR group, compared with the preoperative scores, the VAS scores briefly increased at 3 days postoperation $(\mathrm{P}<0.05)$ and then decreased $(\mathrm{P}<0.05)$. The mean scores of either group at first three follow-up evaluations were significantly different between the two groups $(\mathrm{P}<0.01)$, but not at the 6 -month follow-up $(\mathrm{P}>0.05)$. PFP significantly and immediately improved patients' quality of life as measured by the KPS in the early period after surgery (preoperative vs 3 days postoperative, $\mathrm{P}<0.01$ ), but the patients who underwent
\end{abstract}


PFR suffered a short-term decrease in quality of life (preoperative vs 3 days postoperative, $\mathrm{P}<0.01)$. Blood loss $(\mathrm{P}<0.01)$ and operating time $(\mathrm{P}<0.01)$ were significantly less than PFP. The complication rate was higher in the PFR group (28\%) than in the PFP group (3.6\%). The results also showed no difference in survival time between the two groups. Conclusion: PFP is an attractive minimally invasive therapeutic option for proximal femur metastasis that can significantly improve the patient's quality of life in the short term.

\section{Keywords}

Percutaneous Femoroplasty, Proximal Femoral Replacement, Bone Metastasis, Proximal

\section{Introduction}

Metastatic bone cancers always cause severe pain, particularly on moving [1]. The management of bone metastases requires a multidisciplinary staff who can administer systemic "non-invasive" treatments like radiotherapy, chemotherapy, targeted therapy, and bisphosphonates [2] [3] [4] [5] [6]. However, these "non-invasive" therapeutic regimens leave a high percentage of patients with inadequate or undermanaged pain control [7] [8] [9]. Therefore, "invasive" and "mini-invasive" treatments for proximal femur metastases have been recommended and demonstrated to be effective for controlling cancer-related pain [2] [10] [11] [12]. As we known, a minimally invasive therapeutic option has specific advantages, and an effective and minimally invasive surgical technique are desired for managing advanced cancer patients with severe bone pain who cannot tolerate major surgery or in patients in whom radiotherapy already has been ineffective and who therefore have only the goal of pain relief. Percutaneous femoroplasty (PFP) is being applied more frequently, and initial studies indicate that it may represent an effective method for managing proximal femur metastases [13] [14] [15]. PFP is being applied in treatment of proximal femur metastases by injecting cement into the bone. In the present study, we compared important clinical outcomes after percutaneous femoroplasty (PFP) versus proximal femoral replacement (PFR) to demonstrate the advantages of PFP.

\section{Patients and Methods}

We retrospectively reviewed the records patients with a single proximal femur metastatic lesion treated with PFP or PFR in The Fourth Affiliated Hospital of Hebei Medical University from 2007-2014. The contraindications for surgery by either method were poor general condition and severe comorbidities that impeded the safety of surgery.

PFR involved resection of the metastatic femoral head and neck, curettage of 
any residual lesion (as much as possible in some patients) in the intertrochanteric areas, and then reconstruction with a hip prosthesis. Patients with pathologic fractures were excluded (Figure 1).

PFP was carried out under X-ray or computed tomography (CT) guidance in all cases. Prior to PFP, patients with osteoblastic metastasis in the proximal femur or with an incomplete cortex around the lesion were excluded (Figure 2). Polymethylmethacrylate (PMMA; Mendec Spine High Barium Content Acrylic Resin, Tecres S.P.A, Italy) bone cement was mixed to a semi-liquid consistency and loaded into syringes before injection so that we could easily control the pressure and the amount injected.

We identified 28 consecutive patients treated with PFP and 25 patients treated with PFR. The patient is randomly selected without additional requirements. Together these groups included 26 women and 27 men (53 lesions), with a mean age of 52.9 years (range, 28 - 81 years). The preoperative oncologic status of these patients with regard to primary cancer type, age, sex, and other characteristics are summarized in Table 1. No patients were lost to follow-up, and no patients were recalled specifically for this study. All data were obtained from medical records and radiographs.

Assessments of pain severity according to the visual analog scale (VAS) and of activities of daily life according to the Karnofsky Performance Scale (KPS) before surgery were made at baseline and then 3,7 , and 30 days as well as 6 months

Table 1. Patient characteristics.

\begin{tabular}{|c|c|}
\hline Characteristic & Value \\
\hline \multicolumn{2}{|l|}{ Age (years) } \\
\hline Median & 52.9 \\
\hline Range & $28-81$ \\
\hline Male sex, n (\%) & $26(49)$ \\
\hline \multicolumn{2}{|c|}{ Primary cancer type, n (\%) } \\
\hline Breast & 11 \\
\hline Liver & 13 \\
\hline Lung & 20 \\
\hline Other & 9 \\
\hline \multicolumn{2}{|l|}{ Left or right, n (\%) } \\
\hline Left & $26(49)$ \\
\hline Right & $27(51)$ \\
\hline \multicolumn{2}{|c|}{ Previous treatment, n (\%) } \\
\hline Radiotherapy & $20(38)$ \\
\hline Chemotherapy & $16(30)$ \\
\hline Bisphosphonates & $53(100)$ \\
\hline Targeted therapy & $5(9)$ \\
\hline
\end{tabular}




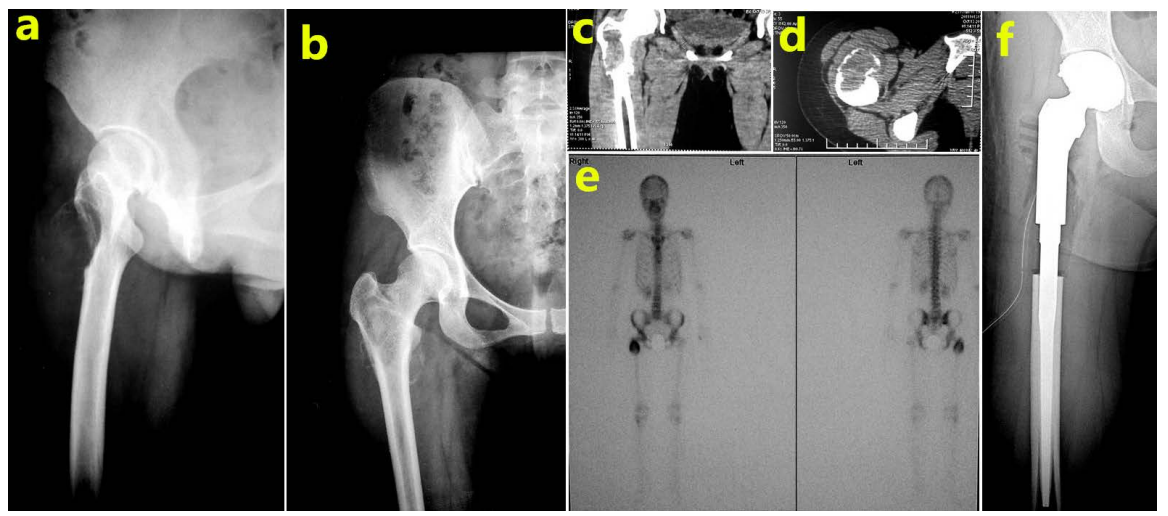

Figure 1. Images of the lesion site of a 28 -year-old female patient presenting with breast cancer and proximal femoral metastases: $(a, b)$ preoperative X-ray images of femoral metastasis; and (c, d) preoperative CT images. (e) Bone scintigraphy. (f) Postoperative X-ray images.

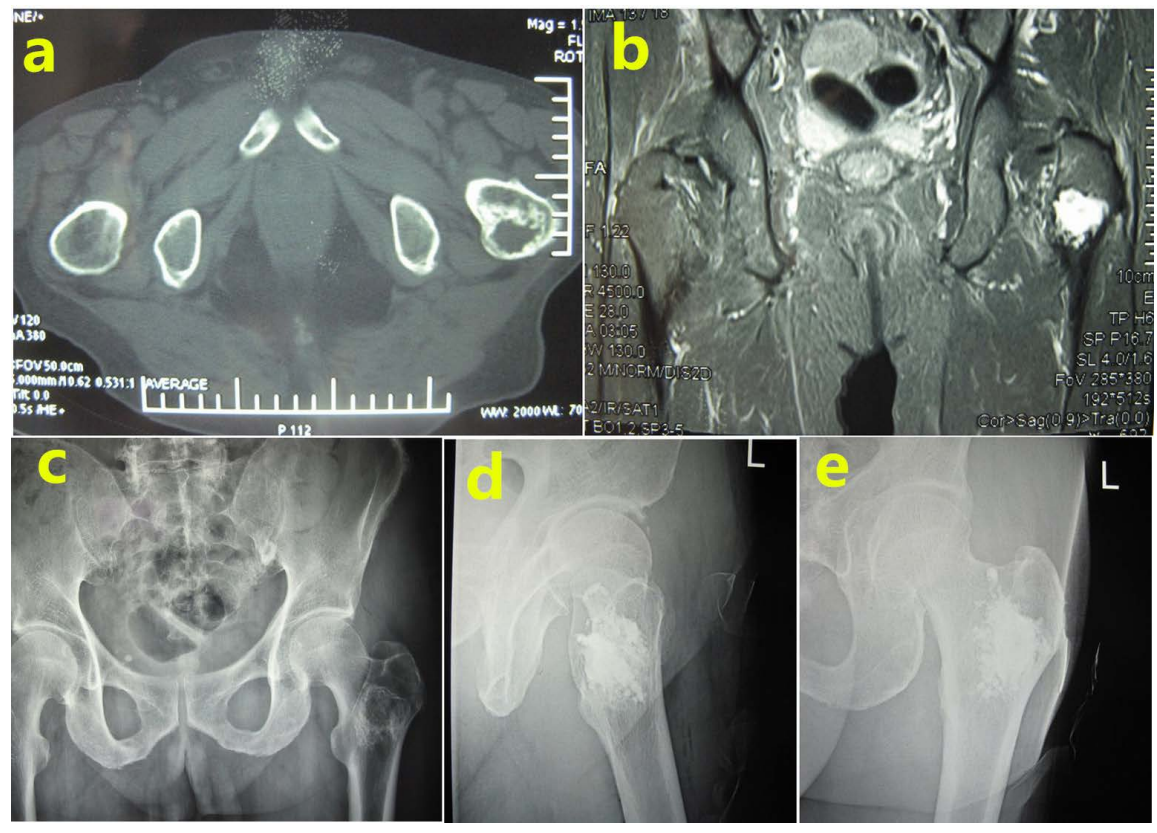

Figure 2. Images of the lesion site in an 81-year-old male patient presenting with lung cancer and left proximal femoral metastasis: (a) preoperative CT image; (b) preoperative coronal magnetic resonance image; (c) preoperative X-ray image of left femoral metastasis; (d) anteroposterior and (e) lateral X-ray images taken at the 6-month follow-up showing that the lesion site was filled with bone cement and no cement leakage could be detected.

postoperatively by personnel qualified to collect such information. Other data such as blood loss and duration of the surgery were recorded individually. $\mathrm{T}$ tests were used for analysis of all data. Medical records and radiographic images for each patient were used to determine and analyze differences in the rates of complications according to $\chi^{2}$ tests. Survival time was calculated from the date of surgery to the date of death or loss to follow-up. The Kaplan-Meier survival curve method was used to estimate the overall survival (OS) rate, and the 
log-rank test was used to evaluate differences in OS between the PFP and PFR groups. SPSS v20 statistical software (SPSS, Inc., Chicago, IL, USA) was used for all statistical analyses, and differences were considered significant if $\mathrm{P}$ was less than 0.05 .

This study complied with the Declaration of Helsinki and was approved by the Human Ethics and Research Ethics Committees of the Fourth Hospital of Hebei Medical University. The participating patient provided written informed consent.

\section{Results}

\subsection{Complications and Operative Parameters}

The complication rate was higher in the PFR group (28\%) than in the PFP group (3.6\%; P $<0.05$ ). The PFP group had 1 person and the PFR group had 7 persons with complications. No complications with serious consequences were observed in the PFP group. Two patients experienced PMMA leakage without a clinical or functional impact. During the surgery, in six cases, the needle was occluded during the filling process, and another needle had to be placed through the same entry site to complete the injection process. No serious complications such as respiratory failure, cardiac arrest, or death occurred in the PFR group either. In this group, complications included dislocations $(n=4$, with one hip dislocating three times), superficial wound infection $(\mathrm{n}=2)$, and one case of acetabular component aseptic loosening requiring revision (Figure 3$)$. Blood loss $(\mathrm{P}<0.05)$ and operative time $(\mathrm{P}<0.01)$ were significantly less in the PFP group compared to the PRF group (Table 2).

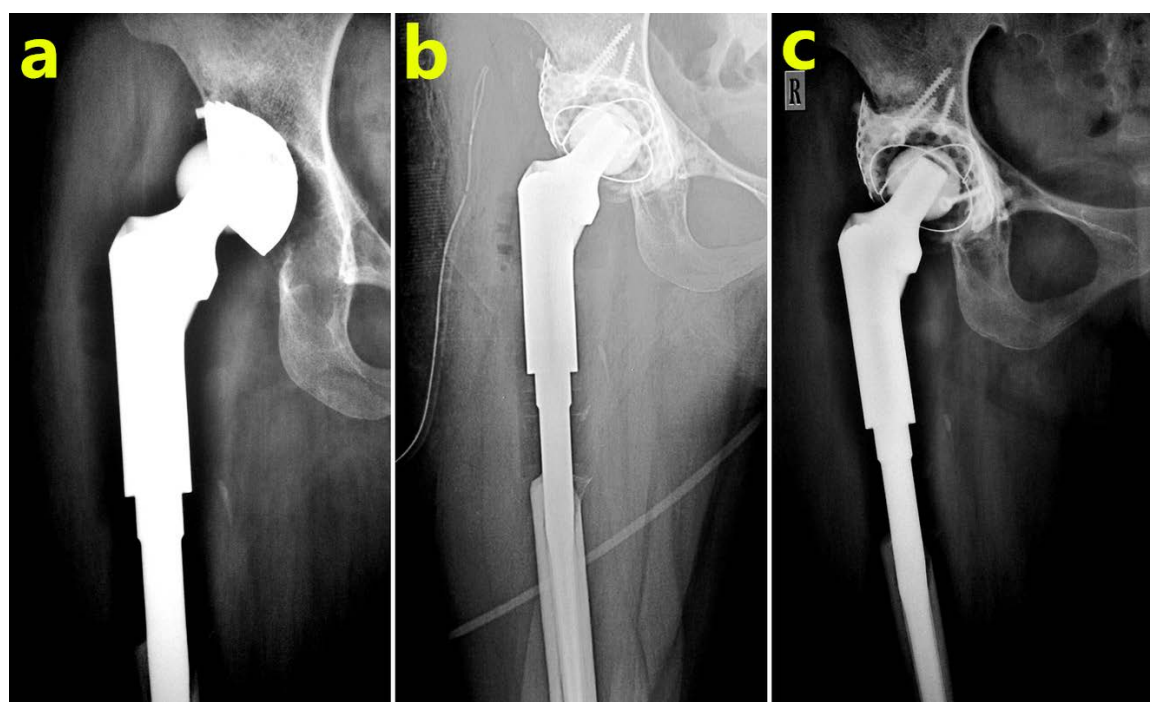

Figure 3. Images of the lesion site of a 28-year-old female patient (the same patient as in Figure 1) who underwent PFR and required revision due to acetabular component aseptic loosening: (a) 23-month follow-up X-ray showed acetabular aseptic loosening; (b) postoperative X-ray images after revision; and (c) 33-month follow-up (10 months after revision). 
Table 2. VAS scores, KPS scores, complications, and operative parameters in the PFP and PFR group.

\begin{tabular}{|c|c|c|c|c|c|c|c|c|c|c|c|c|c|c|}
\hline & \multicolumn{5}{|c|}{ VAS } & \multicolumn{5}{|c|}{ KPS } & \multirow{3}{*}{$\begin{array}{c}\text { Blood } \\
\text { loss } \\
(\mathrm{ml})\end{array}$} & \multirow{3}{*}{ Complications } & \multirow{3}{*}{$\begin{array}{c}\text { Operating } \\
\text { time } \\
\text { (min) }\end{array}$} \\
\hline & & \multirow{2}{*}{ pre-op } & \multicolumn{4}{|c|}{ post-op } & \multirow{2}{*}{ pre-op } & \multicolumn{4}{|c|}{ post-op } & & & \\
\hline & & & $3 \mathrm{~d}$ & $7 \mathrm{~d}$ & $30 \mathrm{~d}$ & $6 \mathrm{~m}$ & & $3 \mathrm{~d}$ & $7 \mathrm{~d}$ & $30 \mathrm{~d}$ & $6 \mathrm{~m}$ & & & \\
\hline \multirow[t]{2}{*}{ PFP } & $\mathrm{M} \pm \mathrm{SD}$ & $\begin{array}{l}\text { ur } \\
\dot{0} \\
1+ \\
+ \\
\dot{a}\end{array}$ & 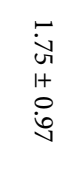 & 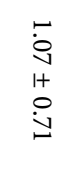 & $\begin{array}{l}0 \\
\text { Ù } \\
1+ \\
0 \\
\text { j్ }\end{array}$ & $\begin{array}{l}0 \\
\dot{0} \\
\text { i } \\
1+ \\
0 \\
\dot{0}\end{array}$ & 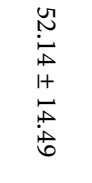 & 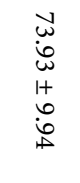 & $\begin{array}{l}\text { y } \\
\infty \\
a \\
1+ \\
\vdots \\
\dot{0} \\
v\end{array}$ & $\begin{array}{l}\infty \\
\stackrel{+}{+} \\
\vdots \\
1+ \\
\dot{b} \\
\dot{b}\end{array}$ & $\begin{array}{l}\infty \\
u \\
1+ \\
o \\
\dot{0}\end{array}$ & \multirow[t]{2}{*}{$\begin{array}{l}\overrightarrow{6} \\
\dot{1} \\
1+ \\
\dot{0} \\
\dot{N}\end{array}$} & \multirow[t]{2}{*}{1} & \multirow[t]{2}{*}{$\begin{array}{l}\underset{\mathscr{D}}{\sim} \\
\dot{v} \\
+ \\
\infty \\
i \\
\infty\end{array}$} \\
\hline & $\mathrm{P}^{*}$ & -- & 0.000 & 0.000 & 0.000 & 0.000 & -- & 0.000 & 0.000 & 0.000 & 0.000 & & & \\
\hline \multirow[t]{3}{*}{ PFR } & $\mathrm{M} \pm \mathrm{SD}$ & $\begin{array}{l}\text { r } \\
\dot{8} \\
1+ \\
\dot{1}\end{array}$ & $\begin{array}{l}u \\
\infty \\
\infty \\
1+ \\
0 \\
\dot{0} \\
\dot{b}\end{array}$ & $\begin{array}{l}n \\
\dot{8} \\
1+ \\
\dot{0} \\
\dot{8}\end{array}$ & $\begin{array}{l}\dot{+} \\
\dot{8} \\
1+ \\
0 \\
\dot{0}\end{array}$ & 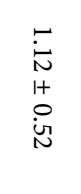 & 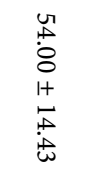 & $\begin{array}{l}w \\
o \\
i \\
\text { î } \\
1+ \\
v \\
\text { in }\end{array}$ & $\begin{array}{l}\frac{1}{\infty} \\
\dot{1} \\
1+ \\
0 \\
\dot{9} \\
\dot{1}\end{array}$ & 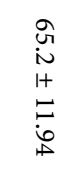 & 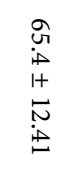 & $\begin{array}{l}\stackrel{\infty}{N} \\
+ \\
\omega \\
\stackrel{\omega}{N} \\
\stackrel{.}{\sigma}\end{array}$ & \multirow[t]{2}{*}{7} & \multirow[t]{2}{*}{$\begin{array}{l}\overrightarrow{\widehat{O}} \\
1+ \\
\uplus\end{array}$} \\
\hline & $\mathrm{P}^{* *}$ & -- & 0.001 & 0.000 & 0.000 & 0.000 & -- & 0.000 & 0.078 & 0.002 & 0.002 & & & \\
\hline & $\mathrm{P}^{* * *}$ & 0.876 & 0.000 & 0.000 & 0.084 & 0.064 & 0.062 & 0.000 & 0.000 & 0.000 & 0.000 & 0.000 & 0.013 & 0.000 \\
\hline
\end{tabular}

\subsection{Pain Relief and Activities of Daily Living}

The preoperative VAS and KPS scores did not differ significantly between the groups $\left(\mathrm{P}_{\mathrm{VAS}}=0.88\right.$ and $\mathrm{P}_{\mathrm{KPS}}=0.06$; Table 2 and Figure 4 and Figure 5$)$. All patients experienced a significant reduction in pain intensity at $7-30$ days after surgery $(\mathrm{P}<0.01)$. However, in the PFP group, patients' quality of life was significantly improved, as measured by the KPS, at the earliest follow-up after surgery (pre-operative to 3 days post-operative, $52.14 \pm 14.49$ to $73.93 \pm 9.94, \mathrm{P}<$ 0.01 ), and the higher KPS scores were maintained at the last follow-up. In contrast, the patients who underwent PFR suffered an immediate decrease in quality of life (pre-operative to 3 days post-operative KPS, $54.14 \pm 14.43$ to $36.40 \pm 7.57$; $\mathrm{P}<0.01$ ). KPS scores in this group then improved (30 days post-operative, 65.20 $\pm 11.94, \mathrm{P}<0.05$ vs. pre-operative) and were stable at last follow-up ( 6 months, $65.4 \pm 12.41)$.

\subsection{Complications and Operative Parameters}

The complication rate was higher in the PFR group (28\%) than in the PFP group (3.6\%; $\mathrm{P}<0.05)$. No complications with serious consequences were observed in the PFP group. Two patients experienced PMMA leakage without a clinical or functional impact. During the surgery, in six cases, the needle was occluded during the filling process, and another needle had to be placed through the same entry site to complete the injection process. No serious complications such as respiratory failure, cardiac arrest, or death occurred in the PFR group either. In this group, complications included dislocations $(n=4$, with one hip dislocating three times), superficial wound infection $(n=2)$, and one case of acetabular component aseptic loosening requiring revision (Figure 3). Blood loss $(\mathrm{P}<0.05)$ and operative time $(\mathrm{P}<0.01)$ were significantly less in the PFP group compared to the PRF group (Table 2). 


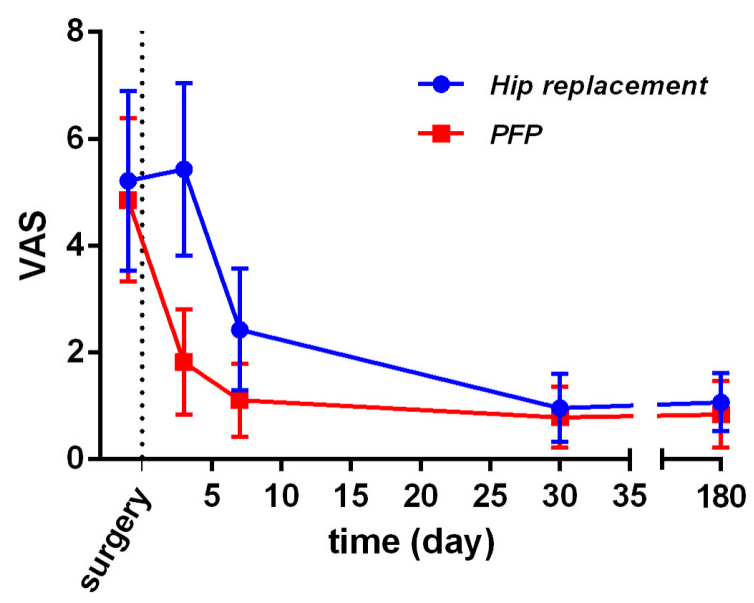

Figure 4. VAS scores in the PFP and PFR groups throughout the study period.

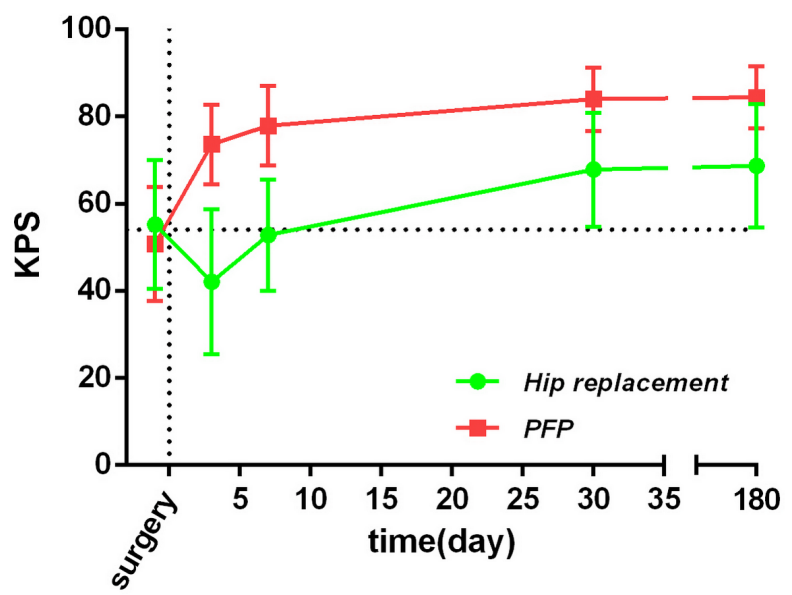

Figure 5. KPS scores in the PFP and PFR groups throughout the study period.

\subsection{Survival Time}

The mortality rate was high in both groups over the mean follow-up for the entire series of 15 months (range, 3 - 36 months). The mean survival times in the PFP and PFR groups were $15.7 \pm 1.5$ months and $16.3 \pm 1.9$ months, respectively, with no significant difference between the groups during the study period ( $\mathrm{P}$ $=0.83$ ). For the overall study population, the OS rate was $88.68 \%$ at 6 months and $59.27 \%$ at 1 year after surgery (Figure 6).

\section{Discussion}

In this retrospective study of patients with proximal femur metastases, PFP provided more immediate pain relief and significantly increased quality of life than PFR without increasing mortality.

The strengths of the present study include that no patient was lost to follow-up and all operations in both groups were performed by the same surgeon. Until now, numerous reports have been published on the subject of proximal femur metastasis treatment, but there has been a lack of retrospective studies 
overall survival

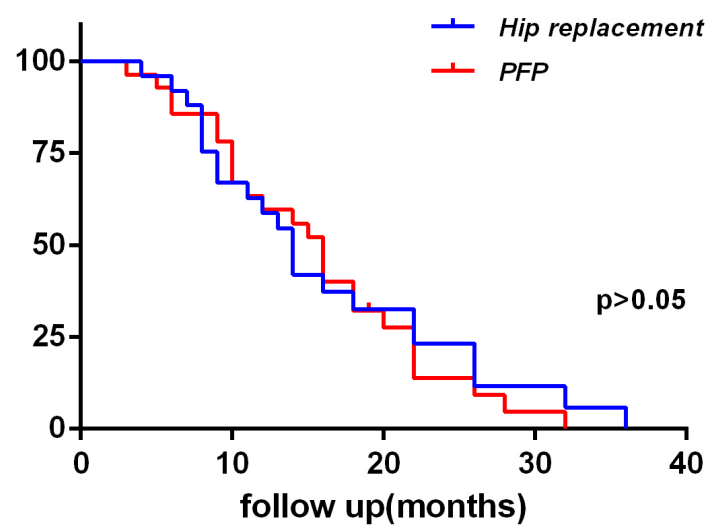

Figure 6. Kaplan-Meier curves for OS in the PFP and PFR groups.

comparing the effectiveness of the two techniques. Such a retrospective follow-up is important due to the increasing incidence of cancer metastasis, especially in the proximal femur.

Proximal femur metastases usually cause pain and can result in pathologic fractures that impede patients' ambulation and decrease their activity level and quality of life. The conventional non-invasive treatment options, including chemotherapy, bisphosphonates, targeted therapy, and radiation therapy, offer inadequate pain control in many patients and are of limited value for the prevention of the pathologic fractures [6] [7] [8] [9]. When a pathological fracture occurs, pain is intensified [16], and without surgical intervention, the patients are bed-ridden and at a greater risk for many complications, resulting in shorter survival times and diminished quality of life [17]. Therefore, invasive surgical treatment is indicated and recommended for patients with proximal femur metastases [18] [19]. The conventional surgical techniques are effective for preventing pathologic fracture and relieving bone pain [20]. However, as the use of PMMA bone cement increases, cementoplasty is more commonly applied to manage painful bone metastases outside the spine and overcome some difficulties that conventional surgical techniques cannot perfectly manage [21].

As an extension of percutaneous vertebroplasty (PVP), PFP can provide immediate and stable pain relief [14] [15] [22], and biomechanical studies have demonstrated that PFP can strengthen mechanical stability for patients with femoral metastases [23] [24] [25]. Moreover, PFP offers the advantages of being a minimally invasive surgery with low requirements for patients' cardiopulmonary function. Although some relative contraindications still exist such as serious deficiencies in liver and kidney function, local infection, and allergy to bone cement, a wider range of patients still are eligible to receive surgical treatment via PFP compared to conventional surgical treatments [26]. The results of our present study are consistent with those of previous studies in that patients treated with PFP experienced pain reduction and improved quality of life soon after surgery [13] [14] [21]. These results show that PFP can lead to satisfactory 
physical rehabilitation, allowing patients to perform basic daily activities. Furthermore, it is important to mention that all patients in the present study also received some specific oncologic treatment such as chemotherapy, radiotherapy, and bisphosphonates. Although studies have shown that these types of therapy can improve patients' quality of life and offer better pain control. However, these methods neither have an immediate curative effect nor effectively repair the loss of mechanical stability caused by bone metastases [20] [27]. In contrast, the outcomes in our series, which suggest the effectiveness of PFP, show that improvements in VAS and KPS scores were seen within only 1 week after intervention.

Because we tested a relatively new surgical technique, we also assessed the associated complications. In our short-time follow-up period, the most frequent complication in the PFP group was cement leakage $(\mathrm{n}=1$, rate $=3.6 \%)$, which caused neither significant clinical symptoms nor an increase in the occurrence of other complications. As previously reported [20], although PFR is effective for treating proximal femur metastases, the high rate of postoperative complications is still troublesome. In addition to a lower rate of postoperative complications observed in our study, PFP was also associated with significantly less blood loss and operative time compared to PFR, indicating that PFP is a less difficult operation. Notably, no patients in either group experienced post-operative fracture, and one possible reason is the short OS after treatment.

The poor survival of patients with bone metastases is an important consideration in treatment planning. Once metastatic tumors are diagnosed, patients have advanced disease, and thus, even with recent advances in treatment for primary cancers, the survival of patients with bone metastases remains poor [28] [29]. Considering the patient's short life expectancy, the major goals of treating bone metastases should be the alleviation of pain, prevention of impending pathological fracture, and improvement in quality of life, beyond just aggressively removing the local bone metastases. The outcomes in our study demonstrate that PFP is an effective option for decreasing pain intensity and can also improve patients' quality of life immediately without causing a difficult short-term recovery period. Furthermore, OS did not differ between the groups. Therefore, PFP may represent not only a surgical alternative for the management of femoral metastases but also a shift in clinical thinking towards terminal cancers.

Inherent limitations of the present study include: 1) the small number of patients and short follow-up period; 2) the lack of clear and complete criteria guiding PFP; and 3) variation in the tumor region. Therefore, randomized controlled trials with long-term follow-up and a large sample size are needed.

When to choose PFP: Patients must have steady vital signs, without severe heart disease, severe lung disease, or topical inflammation and ulceration. The lesion site must be mainly osteolytic damage, and the cortex around the lesion must be complete, especially in the calcar femoral. A pathological fracture cannot be present. This method is not suggested to be applied to osteoblastic metas- 
tases. As a great amount of bone cement is injected into the topical position, it should be done before the bone cement becomes sticky. Pulse oximetry must be monitored closely to avoid pulmonary embolism. Given that bone cement leakage is possible in PFP, once it occurs, the needle should be repositioned under $\mathrm{X}$-ray or CT guidance to prevent further leakage.

\section{Conclusion}

The results in our patient series suggest that PFP, a percutaneous cement placement analogous to vertebroplasty, may be a good therapeutic option for patients with metastatic bone disease of the proximal femur. PFP can significantly improve patients' quality of life and relieve bone pain rapidly while also preventing pathologic fracture and not reducing OS. Thus, PFP may be an attractive surgical treatment for patients with proximal femur metastasis.

\section{Conflicts of Interest}

The authors declare no conflicts of interest regarding the publication of this paper.

\section{References}

[1] Mancini, I., Dumon, J.C. and Body, J.J. (2004) Efficacy and Safety of Ibandronate in the Treatment of Opioid-Resistant Bone Pain Associated with Metastatic Bone Disease: A Pilot Study. Journal of Clinical Oncology: Official Journal of the American Society of Clinical Oncology, 22, 3587-3587. https://doi.org/10.1200/JCO.2004.07.054

[2] Chiras, J., Shotar, E., Cormier, E., et al. (2007) Interventional Radiology in Bone Metastases. Bulletin du Cancer, 94, 161-169.

[3] Heidenreich, A., Ohlmann, C. and Body, J.J. (2004) Ibandronate in Metastatic Bone Pain. Seminars in Oncology, 31, 67-72. https://doi.org/10.1053/j.seminoncol.2004.07.026

[4] Barrett-Lee, P., Casbard, A., Abraham, J., et al. (2014) Oral Ibandronic Acid versus Intravenous Zoledronic Acid in Treatment of Bone Metastases from Breast Cancer: A Randomised, Open Label, Non-Inferiority Phase 3 Trial. Lancet Oncology, 15, 114-114. https://doi.org/10.1016/S1470-2045(13)70539-4

[5] Smith, M.R., Sweeney, C.J., Corn, P.G., et al. (2014) Cabozantinib in Chemotherapy-Pretreated Metastatic Castration-Resistant Prostate Cancer: Results of a Phase II Nonrandomized Expansion Study. Journal of Clinical Oncology, 32, 3391-3399. https://doi.org/10.1200/JCO.2013.54.5954

[6] Li, J., Wang, J., Xu, J., et al. (2017) Percutaneous Femoroplasty with Perioperative Nursing Consultation Relieves Pain in Patients with Metastatic Hip Tumor. Annals of Joint, 2, 14.

[7] Gilbert, H.A., Kagan, A.R., Nussbaum, H., et al. (1977) Evaluation of Radiation Therapy for Bone Metastases: Pain Relief and Quality of Life. American Journal of Roentgenology, 129, 1095-1096. https://doi.org/10.2214/ajr.129.6.1095

[8] Saunders, Y., Edmonds, P.M. and Patel, S. (2004) A Systematic Review of the Role of Bisphosphonates in Metastatic Disease. Health Technology Assessment, 8, 1-176.

[9] Meuser, T., Pietruck, C., Radbruch, L., et al. (2001) Symptoms during Cancer Pain 
Treatment Following WHO-Guidelines: A Longitudinal Follow-Up Study of Symptom Prevalence, Severity and Etiology. Pain, 93, 247-257. https://doi.org/10.1016/S0304-3959(01)00324-4

[10] Xing, Z., Moon, B.S., Satcher, R.L., et al. (2013) A Long Femoral Stem Is Not Always Required in Hip Arthroplasty for Patients with Proximal Femur Metastases. Clinical Orthopaedics \& Related Research, 471, 1622-1627. https://doi.org/10.1007/s11999-013-2790-4

[11] Palussiã"Re, J., Buy, X. and Fonck, M. (2013) Percutaneous Ablation of Metastases: Where Are We and New Techniques. Bulletin du Cancer, 100, 373-379.

[12] Feng, H., Wang, J., Guo, P., et al. (2016) CT-Guided Percutaneous Femoroplasty (PFP) for the Treatment of Proximal Femoral Metastases. Pain Physician, 19, E767-73.

[13] Plancarte-Sanchez, R., Guajardo-Rosas, J., Cerezo-Camacho, O., et al. (2013) Femoroplasty: A New Option for Femur Metastasis. Pain Practice the Official Journal of World Institute of Pain, 13, 409-409. https://doi.org/10.1111/j.1533-2500.2012.00590.x

[14] Plancarte, R., Guajardo, J., Menesesgarcia, A., et al. (2014) Clinical Benefits of Femoroplasty: A Nonsurgical Alternative for the Management of Femoral Metastases. Pain Physician, 17, 227-234.

[15] Feng, H., Feng, J., Li, Z., et al. (2014) Percutaneous Femoroplasty for the Treatment of Proximal Femoral Metastases. European Journal of Surgical Oncology, 40, 402-405. https://doi.org/10.1016/j.ejso.2013.12.015

[16] Tran Thang, N.N., Abdo, G., Martin, J.B., et al. (2008) Percutaneous Cementoplasty in Multiple Myeloma: A Valuable Adjunct for Pain Control and Ambulation Maintenance. Supportive Care in Cancer, 16, 891-896. https://doi.org/10.1007/s00520-007-0344-6

[17] Nilsson, J., Gustafson, P., Fornander, P., et al. (2000) The Harrington Reconstruction for Advanced Periacetabular Metastatic Destruction: Good Outcome in $32 \mathrm{~Pa}-$ tients. Acta Orthopaedica Scandinavica, 71, 591-596. https://doi.org/10.1080/000164700317362226

[18] Biermann, J.S., Holt, G.E., Lewis, V.O., et al. (2009) Metastatic Bone Disease: Diagnosis, Evaluation, and Treatment. Journal of Bone \& Joint Surgery, American Volume, 91, 1518-1530.

[19] Jacofsky, D.J. and Haidukewych, G.J. (2004) Management of Pathologic Fractures of the Proximal Femur: State of the Art. Journal of Orthopaedic Trauma, 18, 459-469. https://doi.org/10.1097/00005131-200408000-00013

[20] Potter, B.K., Chow, V.E., Adams, S.C., et al. (2009) Endoprosthetic Proximal Femur Replacement: Metastatic versus Primary Tumors. Surgical Oncology Oxford, 18, 343-349. https://doi.org/10.1016/j.suronc.2008.08.007

[21] Sun, G., Jin, P., Liu, X.W., et al. (2014) Cementoplasty for Managing Painful Bone Metastases outside the Spine. European Radiology, 24, 731-737. https://doi.org/10.1007/s00330-013-3071-z

[22] Kodama, H., Aikata, H., Uka, K., et al. (2007) Efficacy of Percutaneous Cementoplasty for Bone Metastasis from Hepatocellular Carcinoma. Oncology (Williston Park), 72, 285-292. https://doi.org/10.1159/000113040

[23] Fliri, L., Sermon, A., WãaHnert, D., et al. (2013) Limited V-Shaped Cement Augmentation of the Proximal Femur to Prevent Secondary Hip Fractures. Journal of Biomaterials Applications, 28, 136-143. https://doi.org/10.1177/0885328212443274 
[24] Springorum, R., Gebauer, M., Mehrl, A., et al. (2014) Fracture Prevention by Prophylactic Femoroplasty of the Proximal Femur-Metallic Compared to Cemented Augmentation. Journal of Orthopaedic Trauma, 28, 403-409.

https://doi.org/10.1097/BOT.0000000000000035

[25] Basafa, E. and Armand, M. (2014) Subject-Specific Planning of Femoroplasty: A Combined Evolutionary Optimization and Particle Diffusion Model Approach. Journal of Biomechanics, 47, 2237-2243. https://doi.org/10.1016/j.jbiomech.2014.05.002

[26] Feng, H., Wang, J., Xu, J., et al. (2016) The Surgical Management and Treatment of Metastatic Lesions in the Proximal Femur: A Mini Review. Medicine (Baltimore), 95, e3892. https://doi.org/10.1097/MD.0000000000003892

[27] Smith, H.S. (2011) Painful Osseous Metastases. Pain Physician, 14, E373-E403.

[28] Utzschneider, S., Wicherek, E., Weber, P., et al. (2011) Surgical Treatment of Bone Metastases in Patients with Lung Cancer. International Orthopaedics, 35, 731-736. https://doi.org/10.1007/s00264-010-1074-9

[29] Selek, H., Başarir, K., Yildiz, Y., et al. (2008) Cemented Endoprosthetic Replacement for Metastatic Bone Disease in the Proximal Femur. Journal of Arthroplasty, 23, 112-117. https://doi.org/10.1016/j.arth.2006.11.016 